\title{
STUDI BRANEWORLD DIMENSI LIMA
}

\author{
Dewi Wulandari ${ }^{1, a)}$ \\ ${ }^{1}$ Jurusan Fisika, Fakultas Matematika dan Ilmu Pengetahuan Alam, Universitas Negeri Medan, Jalan Willem \\ Iskandar Pasar V Medan 20221, Indonesia \\ Email: ${ }^{\text {a) } w u l z i e p h y c @ g m a i l . c o m ~}$
}

\begin{abstract}
Abstrak
Studi yang berkaitan dengan braneworld dimensi lima dengan brane tunggal yang terletak di $x^{5}=0$ telah diakukan, model Randall-Sundrum dan modifikasi Randall-Sundrum. Aspek yang ditinjau adalah skalar Ricci, persamaan Einstein, tensor energi-momentum, konsanta kosmologi dan massa Planck efektif dalam dimensi-empat. Dari ekspresi skalar Ricci dan analisis persamaan medan Einstein pada brane dan bulk dapat diinterpretasikan bahwa kedua metrik memiliki ruang-waktu yang berbeda.
\end{abstract}

Kata-kata kunci: Brane-world, Dimensi Ekstra, Model Randall-Sundrum, Model Modifikasi RandallSundrum.

\begin{abstract}
The five-dimensional braneworld models with single brane placed at $x^{5}=0$ have been studied, Randall-Sundrum model and a Modified Randall-Sundrum model. In this case, in terms of Ricci scalar, Einstein equations and energy-momentum tensor, cosmological constant and four-dimensional Planck efective mass have been investigated. From the Ricci scalar and Einstein equation expressions both on brane and bulk indicate that those metrics have different space-time.
\end{abstract}

Keywords:Brane-world, Extra Dimension, Randall-Sundrum Model, Modified Randall-Sundrum Model.

\section{PENDAHULUAN}

Ide skenario braneworld bahwa alam semesta dimensi-empat yaitu t empat medan materi hidup adalah sebuah brane dan brane ini dikurung dalam ruang-waku berdimensi lebih tinggi yang disebut bulk telah memberikan paradigma baru dalam menyelesaikan masalah hirarki dan konstanta kosmologi. Dalam framework braneworld hanya gravitasi yang bebas berpropagasi pada ruangwaktu brane dan bulk sedangkan seluruh medan materi hanya dapat berpropagasi pada brane. Perspektif inilah yang pada akhirnya dapat menjeslakan mengapa interaksi gravitasi sangat kecil dibandingkan dengan interaksi lain, sehingga dalam model sandar pengaruh efek gravitasi dapat diabaikan.

Salah satu model braneworld yang cukup popular adalah model Randall-Sundrum, dengan satu dimensi tambahan (koordinat-y). Lisa Randall dan Raman Sundrum $[1,2]$ mengusulkan model braneworld tipe I dan II. Dalam model Randall-Sundrum I dibangun berdasarkan asumsi terdapat dua buah brane yang identik yang terletak pada $y=0$ yang disebut dengan Planck brane (invisible brane) dan 
visible brane yang terleak pada $y=\pi r=L$, dimana $L$ adalah jarak antara kedua brane. Model Randall-Sundrum I ini memberikan pendekatan untuk menyelesaikan masalah hirarki. Model Randall-Sundrum II diusulkan hanya ada satu brane yang digunakan untuk menganalisis prilaku medan materi dalam brane termasuk sifat lokalisasi.

Mekanisme lokalisasi medan materi pada brane secara natural menjadi sesuatu yang penting dalam framework brane world. Tidak semua medan materi dapat terlokalisasi pada brane metrik Randall-Sundrum [3,4,5]. Mengacu pada referensi [6,7] yang mengusulkan metrik dimensi-lima (koordinat-r) yang merupakan modifikasi metrik Randall-Sundrum ternyata menghasilkan sifat lokalisasi yang cukup berbeda jika dibandingkan dengan metrik asli Randall-Sundrum. Medan vektor spin-1yang tidak dapat terlokalisasi pada brane metrikasli Randall-Sundrum ternyata dapat terlokalisasi pada brane metrik modifikasi Randall-Sundrum untuk kasus decreasing warp factor. Hal yang cukup menarik terjadi untuk kasus medan skalar bermassa yang terlokaliasi pada brane metrik modifikasi Randall-Sundrum yaitu munculnya mekanisme pembangkit massa sendiri yang mengingatkan pada mekanisme self-consistent Nambu dan Jona-Lasinio [8].

Perbedaan sifat lokalisasi medan materi pada metrik asli Randall-Sundrum dengan metrik modifikasi Randall-Sundrum membawa ketertarikan untuk menganalisis aspek-aspek yang berkaitan dengan kedua metrik dimensi-lima ini. Aspek yang dikaji meliputi ekpresi skalar Ricci, persamaan medan Einstein, konstanta kosmologi, tensor energi-momentum dan massa Planck efektif.

\section{METRIK BRANE WORLD DIMENSI LIMA}

Aksi dari gravitasi untuk model brane world dimensi lima dengan melibatkan konstanta kosmologi didefenisikan sebagai berikut [3-5]:

$$
S_{g}=-\frac{1}{2 \kappa^{2}} \int d^{5} x \sqrt{g} R_{5}+\frac{\Lambda}{\kappa^{2}} \int d^{5} x \sqrt{g}+S_{\text {materi }}
$$

dimana $g$ adalah determinan tensor metrik dimensi-lima, $R_{5}$ adalah skalar Ricci dimensi-lima, $\Lambda$ adalah konstanta kosmologi dan $\kappa$ adalah konstanta kopling.

Metrik yang diusulkan dalam model Randall-Sundrum didefensikan:

$$
d s_{[y]}^{2}=e^{-2 k|y|} \eta_{\mu \nu} d x^{\mu} d x^{\nu}-d y^{2},
$$

dimana $\eta_{\mu v}=\operatorname{diag}(1,-1,-1,-1)$ adalah metrik Minkowski dimensi-empat, $k$ adalah konstanta yang diperoleh dari persamaan Einstein melalui ketertalaan (fine-tuning) dengan konstanta kosmologi.

Metrik yang diusulkan pada referensi [6,7] yang merupakan metrik modifikasi model RandallSundrum didefensikan:

$$
d s_{[r]}^{2}=e^{-2 k|r|} \eta_{\mu \nu} d x^{\mu} d x^{\nu}-e^{-2 k|r|} d r^{2}
$$

Pada metrik modifikasi Randall-Sundrum, warp factor, $a=e^{-k\left|x^{5}\right|}$ tidak hanya muncul pada komponen dimensi-empat tapi juga muncul pada komponen dimensi ekstra. Metrik (3) juga dapat ditulis dengan $d s_{[r]}^{2}=e^{-2 k|r|} \eta_{A B} d X^{A} d X^{B}$. Dari perspektif dimensi-empat, metrik (2) dan (3) dapat dihubungkan dengan koordinat transformasi $e^{-k|r|} d X^{\mu}=e^{-k|y|} d x^{\mu k}$ dan untuk komponen dimensi ekstra dinyatakan dengan $d y=e^{-k|r|} d r$. Kedua metrik (2) dan (3) secara konformal adalah flat dengan koordinat tranformasi untuk komponen dimensi ekstra pada metrik (2) didefenisikan dengan $d y^{2}=e^{-2 k|y|} d z^{2}[9-11]$. 
Nilai symbol Christofell dan tensor Ricci yang tidak nol untuk metric koordinat-y adalah:

$$
\begin{gathered}
\Gamma_{\mu v[y]}^{5}=k e^{-2 k|y|} \eta_{\mu v} \Gamma_{5 \mu[y]}^{v}=-k \delta_{\mu \mu}^{v}, \\
R_{\mu v[y]}=\left(4 k^{2}-2 k \delta(y)\right) e^{-2 k|y|} \eta_{\mu v} ; \\
R_{55[y]}=4 k^{2}-8 k \delta(y),
\end{gathered}
$$

dan Skalar Ricci untuk metrik (2) didefenisikan sebagai berikut:

$$
R_{[y]}=-20 k^{2}+16 k \delta(y),
$$

Nilai symbol Christofell dan tensor Ricci yang tidak nol untuk metric koordinat-r adalah:

$$
\begin{gathered}
\Gamma_{\mu v[r]}^{5}=k \eta_{\mu v} ; \Gamma_{5 \mu[r]}^{v}=-k \delta_{\mu}^{v} ; \Gamma_{55[r]}^{5}=-k, \\
R_{\mu v[r]}=\left(4 k^{2}-2 k \delta(r)\right) \eta_{\mu v} ; R_{55[r]}=-8 k \delta(r),
\end{gathered}
$$

dan skalar Ricci untuk metrik (3) didefenisikan sebagai berikut:

$$
R_{[r]}=-12 k^{2} e^{2 k r}+16 k \delta(r) e^{2 k r} .
$$

Ekspresi dari tensor Ricci dan skalar Ricci yang berbeda dari kedua metrik tersebut mengidentifikasi bahwa kedua metrik merepresentasikan ruang-waktu yang berbeda.

Dengan memberlakukan prinsip variasi aksi terkecil pada aksi (1) terhadap metrik $g_{A B}$, maka diperoleh persamaan medan gravitasi, persamaan Einstein dalam dimensi-lima:

$$
G_{A B}+g_{A B} \Lambda=\kappa^{2} T_{A B},
$$

dimana $G_{A B}$ adalah tensor Einstein dimensi-lima, $T_{A B}$ adalah tensor energi-momentum yang menggambarkan distribusi materi dan energi yang didefenisikan melalui persamaan sebagai berikut:

$$
T_{A B}=\frac{2}{\sqrt{g}} \frac{\delta S_{\text {materi }}}{\delta g^{A B}} .
$$

Tensor Einstein pada brane untuk masing-masing sistem koordinat didefenisikan sebagai berikut:

$$
\begin{gathered}
G_{\mu v}=6 \eta_{\mu v} k^{2} e^{-2 k|y|}-6 \eta_{\mu v} k \delta(y), \\
G_{\mu v}=3 \eta_{\mu v} k^{2}-6 \eta_{\mu v} k \delta(r),
\end{gathered}
$$

dan tensor Einstein pada bulk:

$$
G_{55[y]}=G_{55[r]}=-6 k^{2} \text {. }
$$

Dengan mensubsitusi komponen tensor Einstein untuk masing-masing sistem koordinat kepersamaan (6a), maka diperoleh persamaan medan Einstein pada brane sebagai berikut:

$$
\begin{gathered}
\kappa^{2} T_{\mu v}=6 \eta_{\mu v} k^{2} e^{-2 k|y|}-6 \eta_{\mu v} k \delta(y)+e^{-2 k|| y \mid} \eta_{\mu v} \Lambda_{[y]}, \\
\kappa^{2} T_{\mu v}=3 \eta_{\mu v} k^{2}-6 \eta_{\mu v} k \delta(r)+e^{-2 k v} \eta_{p v} \Lambda_{[r]} .
\end{gathered}
$$


Kehadiran fungsi delta pada persamaan (9a) dan (9b) menginterpretasikan bahwa sumber materi yang diindikasikan dengan tensor energi-momentum terkurung pada brane yang berada pada titik $x^{5}=0$.

Persamaan Einstein pada bulk didefenisikan sebagai berikut:

$$
\begin{gathered}
\kappa^{2} T_{55}=-6 k^{2}-\Lambda_{[y]}, \\
\kappa^{2} T_{55}=-6 k^{2}-e^{-2 k r} \Lambda_{[r]} .
\end{gathered}
$$

Dalam model Randall-Sundrum, ruang-waktu bulk merupakan ruang-waktu Anti de-Sitter yang dikarakteristik dengan konstanta kosmologi yang bernilai negatif. Karena di dalam bulk tidak ada materi (vakum) maka $T_{55}=0$, sehingga melalui ketertalaan dengan konstanta kosmologi, akan diperoleh $\Lambda_{[y]}=-6 k^{2}$.

Dari hasil yang diperoleh di atas, maka dapat didefenisikan tensor energi-momentum pada brane untuk model Randall-Sundrum sebagaiberikut:

$$
T_{\mu v}=\frac{6 \eta_{\mu \nu} k \delta(y)}{\kappa^{2}}
$$

dan tegangan brane (brane tension) didefenisikan sebagai berikut:

$$
\sigma=\frac{6 k}{\kappa^{2}}=\frac{\sqrt{-6 \Lambda_{[y]}}}{\kappa^{2}} .
$$

Dari persamaan (12) diperoleh ketertalaan (fine-tuning) antara konstanta $k$, konstanta kosmologi, $\Lambda_{[y]}$ dan juga tegangan brane, $\sigma$. Dari perumusan persamaan (6b) dan (11) dapat disimpulkan, dalam model Randall-Sundrum, $S_{\text {materi }}$ dapat diindikasikan oleh fungsi delta tegangan brane dimensiempat yaitu, $\sigma \delta(y)$. Hal yang berbeda terjadi pada modifikasi Randall-Sundrum, $S_{\text {materi }}$ yang diperoleh tidak hanya diindikasikan oleh fungsi delta tegangan brane tetapi juga diindikasikan oleh momentum-energi bulk.

Untuk modifikasi Randall-Sundrum, dari persamaan (9a) dan (10b), tidak memungkinkan mendapatkan ketertalaan (fine-tuning). Hal paling sederhana yang dapat dilakukan adalah dengan mendefenisikan $\Lambda_{[r]}=0$, sehingga tensor energi-momentum untuk sistem koordinat- $r$ didefenisikan sebagai berikut:

$$
\begin{gathered}
\kappa^{2} T_{\mu \nu}=2 k \eta_{\mu v}(k-2 \delta(r)) \\
\kappa^{2} T_{55}=-6 k^{2}
\end{gathered}
$$

Dari persamaan (13b) diperoleh komponen kelima tensor energi-momentum merupakan konstanta bulk, $T_{55}=-6 k^{2} / \kappa^{2}$ sedangkan komponen tensor energi-momentum dimensi-empat, $T_{\mu \nu}$ didefenisikan dengan suku konstanta bulk $3 k^{2}$ dan suku fungsi delta, $-6 k \delta(r)$. Fungsi delta dirac mengindikasikan distribusi materi yang terkurung dalam brane. Untuk pengamat yang terkurung dalam brane, tensor energi-momentum efektif dimensi empat akan muncul sebagai suku konstanta kosmologi efektif dimensi-empat [6], $T_{\mu \nu}^{4 D}=\Lambda_{4 \mathrm{D}} \eta_{\mu \mathrm{v}}$ dengan $\Lambda_{4 \mathrm{D}}=3 k^{2}-6 k$. Konstanta kosmologi efektif dapat bernilai negatif untuk $0<k<2$ dan positif untuk $k<0$ atau $k>2$. Untuk $k=2$, konsanta kosmologi efektif akan lenyap. Dari kondisi lokalisasi medan skalar yang terkopel dengan medan vektor [12], medan skalar bermassa maupun tak bermassa dan medan vektor tak bermassa dapat terlokaliasi pada brane metrik modifikasi Randall-Sundrum untuk kasus decreasing warp factor 
dengan $k=1$. Kondisi ini akan memberikan nilai konstanta kosmologi negatif yang mengindikasikan ruang-waktu Anti de-Sitter.

\section{MASSA PLANCK EFEKTIF DIMENSI EMPAT}

Konstanta gravitasi Newton, $G$ dapat dikaitkan dengan massa Plank melalui persamaan berikut ini:

$$
G=\frac{1}{M_{p l}^{2}}
$$

Massa Planck efektif dimeni-empat, diperoleh dengan membandingkan aksi gravitasi dalam dimensi-lima dengan aksi gravitasi dalam dimensi-empat,

$$
S=-\frac{1}{\kappa^{2}} \int d^{5} x \sqrt{g} R_{5}=-\frac{M_{5}^{3}}{16 \pi} \int d^{5} x \sqrt{|g|} R_{5},
$$

dengan $|g|$ adalah determinan metrik dimensi-lima, $M_{5}$ adalah massa Planck dalam dimensi lima, dan $R_{5}$ adalah skalar Ricci dalam dimensi-lima. Untuk metrik asli model Randall-Sundrum (2), $\|g\|=e^{-8 k \mid y \|}$ det $_{\mu v}$, skalar Ricci dalam dimensi-lima dapat dijabarkan sebagai berikut:

$$
R=g^{\mu v} R_{\mu v}+\ldots=e^{-2 k|y|} \eta^{\mu v} R_{\mu v}+\ldots=e^{-2 k|y|} R_{4}+, . .
$$

Sehingga aksi dimensi-lima untuk model asli Randall-Sundrum didefenisikan sebagai berikut:

$$
\begin{aligned}
S & =-\frac{M_{5}^{3}}{16 \pi} \int d^{5} x \sqrt{|g|} R_{5} \\
& =-\frac{M_{5}^{3}}{16 \pi} \int d^{5} x e^{-4 k|y|} \sqrt{\operatorname{det} \eta_{\mu \nu}}\left(e^{-2 k|y|} R_{4}+\ldots\right) \\
S & =-\frac{M_{5}^{3}}{16 \pi} \int d^{4} x e^{-4 k|y|} \sqrt{\operatorname{det} \eta_{\mu \nu}} \int d y e^{-2 k|y|} R_{4}+\ldots
\end{aligned}
$$

Jika persamaan (17) diintegralkan terhadapdimensi-ekstra ( $=0$ sampai $y=\infty)$ maka persamaan (17) akan menjadi:

$$
S=-\frac{M_{5}^{3}}{16 \pi} \int d^{4} x \frac{1}{2 k} \sqrt{\operatorname{det} \eta_{\mu \nu}} R_{4}+\ldots
$$

dan aksi gravitasi dalam dimensi-empat didefenisikan sebagai berikut:

$$
S=-\frac{1}{16 \pi G} \int d^{4} x \sqrt{g_{4}} R_{4}
$$

Dengan membandingkan persamaan (18) dan (19) dan dengan menggunakan hubungan persamaan (14), maka massa Planck efektif dimensi-empat dalam model Randall Sundrum diperoleh sebagai berikut: 


$$
M_{p l[y]}^{2}=\frac{M_{5}^{3}}{2 k}
$$

Dengan cara yang sama, untuk brane metrik modifikasi Randall-Sundrum, $|g|=e^{-10 k}|r| d e t \eta_{\mu v}$, skalar Ricci, $R=e^{-2 k|r|} R_{4}+\cdots$, maka massa Planck efektif dimensi-empat dalam model modifikasi Randall Sundrum diperoleh sebagai berikut:

$$
M_{p l[r]}^{2}=\frac{M_{5}^{3}}{3 k}
$$

Dari persamaan (20) dan (21) dapat disimpulkan, untuk kedua model braneworld dimensi lima ini dengan brane tunggal, meskipun dimensi ekstra berukuran besar (menuju tak berhingga), nilai massa Planck efektif belum tereduksi mendekati orde skala elektroweak karena hanya bergantung pada massa Planck dimensi-lima dengan konstanta $\mathrm{k}$.

\section{SIMPULAN}

Ekspresi dari skalar Ricci dan analisis persamaan medan Einstein mengindikasikan ruang-waktu yang didefenisikan dari metrik asli Randall-Sundrum dan metrik modifikasi Randall-Sundrum merepresentasikan ruang-waktu yang berbeda.

Dari persamaan Einstein pada bulk, untuk model Randall-Sundrum memungkinkan melakukan ketertalaan yang menyebabkan lenyapnya komponen kelima tensor energi-momentum dan diperoleh hubungan $\Lambda_{[y]}=-6 k^{2}$, sedangkan untuk model modifikasi Randall-Sundrum tidak memungkinkan melakukan ketertalaan tetapi dengan mendefenisikan $\Lambda_{[r]}=0$.

Melalui keterkaitan antara tensor energi dengan aksi materi, pada model Randall-Sundrum, $S_{\text {materi }}$ didefenisikan dalam fungsi delta tegangan brane, $\sigma \delta(y)$ sedangkan pada model modifikasi RandallSundrum $S_{\text {materi }}$ tidak hanya didefenisikan dalam fungsi delta tegangan brane, $\sigma \delta(y)$ tetapi disertai suku konstanta momentum-energi bulk, $3 k^{2}$.

Dari rumusan massa Planck efektif dimensi-empat, meskipun dengan dimensi ekstra yang besar (tak berhingga) untuk kedua model brane world, tidak membuat massa Planck tereduksi mendekati orde skala elektroweak.

\section{UCAPAN TERIMAKASIH}

DW mengucapkan terimakasih atas dukungan beasiswa BPPDN DIKTI. Penelitian ini didanai oleh DIKTI melalui hibah disertasi tahun 2016.

\section{DAFTAR ACUAN}

[1] Randall, L., dan Sundrum, R., Phys. Rev. Lett. 83, 3370 (1999).

[2] Randall, L., dan Sundrum,R., Phys. Rev. Lett. 83, 4690 (1999).

[3] M. Gogberashvili, Int. J. Mod. Phys. D 11, 1635 (2002)

[4] A. Pomarol, Phys. Lett. B 486, 153 (2000)..

[5] B. Bajc and G. Gabadadze, Phys. Lett. B 474, 282 (2000).

[6] Jones P., Singleton D., Triyanta, Phys. Rev. D 88, 025048 (2013)

[7] Triyanta, D. Singleton, P. Jones, G. Munoz, AIP Conference Proceedings 1617, 96 (2014). 
[8] Y. Nambu and G. Jona-Lasinio, Phys. Rev. 122, 345 (1961).

[9] A. Perez-Lorenzana, arXiv: hep-ph/04066279

[10] K. Koyama, J. Comol. Asropart. Phys. 09 (2004) 010

[11] N. Arkani-Hamed, S. Dimopoulos, G. Dvali, and N. Kaloper, Phys. Rev. Lett. 84, 586 (2000).

[12] D. Wulandari, Triyanta, Jusak S. Kosasih, D. Singleton AIP Conference Proceedings 1677, 040003 (2015) 
